\title{
O PROJETO ESTÉTICO-FILOSÓFICO EM ADORNO: ARTICULAÇÕES ENTRE OS CONCEITOS DE CONCRETO, APROXIMAÇÃO E CONSTRUÇÃO
}

Aesthetic-PhILOSOPHICAL PROJECT IN AdORNO: ARTICULATIONS AMONG THE CONCEPTS OF CONCRETE, APPROXIMATION AND CONSTRUCTION

Mauricio João Farinon*

\begin{abstract}
RESUMO - A Teoria Crítica propõe, com Theodor Adorno, uma íntima relação entre filosofia e desenvolvimento de experiências formativas, constituindo um referencial teórico indispensável para o entendimento acerca do que é pensar filosoficamente em uma perspectiva denominada negativa. Nessa relação, a experiência e racionalidade estética demarcam uma nova forma de conceber a razão e seu momento na relação com a objetividade. Esse momento da razão não indica apropriação, mas remete para uma aproximação e, a partir dessa, a construção de sentido. A problemática que orienta este texto indaga sobre como os conceitos de concreto, aproximação e construção se articulam no desenvolvimento das chamadas experiências formativas. Defendemos a hipótese de que a partir da articulação desses conceitos a riqueza constitutiva da realidade passa a ser manifestada e apreendida, possibilitando, mediante a ampliação das experiências, a manifestação do novo e a construção de sentido. Essa constelação conceitual indica o desafio de considerar a objetividade para além do imediatamente dado; indica, também, o sentido que deve assumir a tensão dialética geradora da aproximação e, por último, um caminho que nos auxilia na tarefa de compreensão do pensamento crítico de Theodor Adorno.
\end{abstract}

PALAVRAS-CHAVE - Adorno. Pensamento filosófico. Concreto. Aproximação. Construção.

ABSTRACT - The Theodor Adorno's Critical Theory offer a close relationship between philosophy and the development of formative

* Mestre em Filosofia e Doutor em Educação pela PUCRS. Professor na Universidade de Passo Fundo (UPF), na área de Ética e Conhecimento. <mauriciojfarinon@gmail.com>.

\begin{tabular}{|l|l|l|l|l|l|}
\hline Veritas & Porto Alegre & v. 57 & n. 3 & set./dez. 2012 & p. 8-31 \\
\hline
\end{tabular}


experiences, constitutes an indubitable theoretical reference for understanding with is philosophically thinking in the so-called negative perspective. In this relation, the experience and aesthetic rationality delimit a new way to conceive reason and its moment in relation to objectiveness. This moment of the reason does not indicate appropriation but refers for a approximation and from this to the construction of meaning. The problematic that orientates this text enquires about how the concepts of concrete, approximation, and construction articulate in the development of formative experiences. Defending the hypothesis that from the articulation of this concepts the wealth constitutive of reality becomes to be manifested and learned, leading through the extension of experiences to the manifestation of the new and the construction of meaning. This conceptual constellation indicates the challenge to consider the objectiveness for beyond of the immediately given; also points to the sense that must assume the dialectic that generates approximation and for last, the path that help us in the task to comprehend the critical thinking of Theodor Adorno.

KEYWORDS - Adorno. Philosophical thought. Concrete. Approximation. Construction.

O ponto de partida que orienta essa investigação é a experiência estética em sentido amplo. Ou seja, se, por um lado, a estética se relaciona com os processos produtivos e perceptivos que envolvem as obras de arte, por outro, ela encontra em Adorno uma ênfase naquilo que é possível denominar encontro sensível. Na constituição desse encontro, por ele ser sensível, o núcleo está posto no modo como somos tocados pelo outro, enquanto corporeidade com a qual se estabelece relação. Situando teoricamente, a Mínima moralia aponta para a necessidade de desenvolvermos a dialética do tato, essa capacidade de relação com a corporeidade enquanto algo que é, privilegiadamente, sensível. É possível conceber - ainda introdutoriamente - que, desse modo, a estética retoma as bases sensíveis da razão.

Essa compreensão se assenta em um fragmento encontrado ainda na obra de Adorno, denominada Kierkegaard: a construção do estético. Nessa obra, Adorno analisa o pensamento do referido filósofo e observa três sentidos para o termo estética. No primeiro, "como no uso comum da linguagem, chama-se estético o domínio das obras de arte e das ponderações de teoria da arte"; no segundo, temos "o estético como atitude ou, segundo seu uso linguístico posterior, como "esfera'"; por último, "o estético referido à forma da comunicação subjetiva, e se legitima no conceito kierkegaardiano de existência [...]. Por isso seu pensar tem uma outra posse, pela qual ele pertence ao sujeito e a nenhum 
outro" ${ }^{1}$. Partindo do primeiro sentido, enfatizaremos, neste texto, o segundo e terceiro, os quais têm grande ressonância nas obras posteriores, principalmente a Dialética negativa. Essa ressonância está assentada na experiência artística, mas se amplia - e aqui está nosso objeto de estudo -, enquanto atitude ou comunicação, como uma racionalidade que define o modo de perceber também o outro ser humano.

No primeiro sentido acima exposto, a referência é clara, por se dirigir a um objeto específico denominado obra de arte e a investigação teóricofilosófica que se realiza a partir dela. Porém, os dois sentidos posteriores remetem o pensamento estético à consideração do ser humano em seu estado atual, com um interesse especial ao pensamento mesmo, como posse do sujeito e, também, ao não imediato que caracteriza o ser sensível. Desse modo, pensar esteticamente consiste no olhar atento ao homem e aquilo que ele é de forma imediata, enquanto ser que se constitui mediante as experiências com o mundo empírico. O contraponto ético, conforme cita Adorno, considera a mudança e o motivo que leva a se tornar aquilo que se torna. De modo que, se o estético é o olhar sobre aquilo que o ser humano é imediatamente, o ético é o olhar sobre aquilo que o ser humano pode vir a ser.

O diferencial em Adorno é que o próprio domínio e consideração teórica da arte já é, por si mesmo, análise do ser humano em sua existência imediata e em suas possibilidades de devir. Pelo fato de a arte ter se tornado o que se tornou, "antítese social da sociedade", falar sobre ela é falar sobre o meio pelo qual e no qual surge. No momento em que a arte se contrapõe à realidade, se constitui em forma de conhecimento, pois sua tarefa não é mais afirmar, mas ser tensão, provocando o movimento dialético do pensamento - a antítese entre o pensamento e aquilo que ele mesmo não é; antítese entre a arte e o meio no qual ela aparece.

O comportamento estético próprio do ser sensível que cria consciência mediante a experiência desenvolvida, assume a marca da contradição ao princípio de realidade, a qual põe a adaptação como o bem supremo. A frase "a realidade oferece muitos outros motivos reais para dela se fugir" ${ }^{2}$ não expressa a fuga propriamente dita, como uma patologia psíquica, mas remete ao termo resistência, muito desenvolvido na Educação e emancipação e na Minima moralia. Nesta compreensão da estética como atitude, a realidade não tem o poder supremo de atuar sobre o indivíduo determinando-o ou reprimindo-o, pelo contrário, enquanto consideração

ADORNO, T. Kierkegaard: construção do estético. Tradução de Álvaro L. M. Valls. São Paulo: Editora UNESP, 2010. p. 43-45.

2 ADORNO, T. Teoria estética. Tradução de Artur Morão. Lisboa: Edições 70, 1993. (Arte e Comunicação: 14). p. 20. 
do estado em que o humano se encontra como ser real, a capacidade de compreensão e atribuição de sentido exige a dose de resistência acusada por Adorno como indispensável ao entendimento da realidade não enquanto aparência imediata - afinal essa é muito bem administrada -, mas como um espetáculo que ocorre nos bastidores.

Frente a isso a obra de arte assume vinculação ao processo de esclarecimento, ao não ser simples cópia do empírico ou daquilo que acontece na superfície da existência, mas trazendo para frente do palco aquilo que ocorre nos bastidores:

O embuste [...] consiste precisamente em que esta harmonização da vida e esta deformação da vida são imperceptíveis para as pessoas, porque acontecem nos bastidores [...], de modo que as pessoas absorvem a harmonização oferecida sem ao menos se dar conta do que lhes acontece. Talvez até mesmo acreditem estar se comportando de modo realista. $\mathrm{E}$ justamente aqui é necessário resistir³

Esta forma distinta de reflexão é o ato de pensamento, vinculado ao processo de esclarecimento exigido ainda nas linhas da Dialética do esclarecimento, e que remete não somente ao terceiro sentido que o termo estética assume em Kierkegaard e é analisado por Adorno como sendo um interesse especial pelo próprio pensamento enquanto posse do sujeito, ou seja, a necessidade de pensar o próprio pensamento. Vinculado a isso está a possibilidade de resistir às formas padronizadas de pensamento, a partir das quais passamos a compreender os fatos e, como resposta ao problema de tais padrões, propõe-se a constituição de um lócus comunicativo por meio do qual se amplia o nível de experiências e de compreensão, cuja consequência é um retorno qualificado ao próprio pensamento de modo autocrítico, quanto à possibilidade de perceber o diferenciado - aquilo que permite a identidade de si, suas características próprias e que impedem a simples universalização - a partir do local ocupado por ele. A isso Adorno denomina, no texto Observações sobre o pensamento filosófico ${ }^{4}$, de "comunicação do diferenciado".

O conceito de comunicação ${ }^{5}$ assume a postura de que o diferente deve ser compartilhado, sendo, inclusive, diferenciação em nível de experiências de mundo. Isso se relaciona com o modo como Adorno concebe a própria linguagem, não enquanto simples modo de comunicação, mas enquanto

3 ADORNO, T. Educação e emancipação. 3. ed. Tradução de Wolfgang Leo Maar. São Paulo: Paz e Terra, 2003. p. 86.

4 ADORNO, T. "Observações sobre o pensamento filosófico". In: Palavras e sinais: modelos críticos 2. Tradução de Maria Helena Ruschel. Petrópolis: Vozes, 1995. p. 184.

5 Retornaremos ao conceito de comunicação e linguagem, na parte final deste texto. 
"meio de expressão rigorosa do objeto" ${ }^{6}$, a partir da qual seja possível gerar o entendimento. O problema está, então, na incapacidade de comunicação, nos traços de incomunicabilidade própria de indivíduos incapazes de perceber no diferenciado um impulso para o conhecimento e, consequentemente, incapazes de rigor expressivo. A linguagem tem a obrigação de expressar rigorosamente aquilo que se quer comunicar, o que nos remete ao conceito de experiência e ampliação das experiências formativas, pelas quais se tem condições de evitar o problema exposto na Dialética negativa, acerca da relação entre expressão e rigor.

Por mais que um paralelo necessário seja encontrado em Habermas e sua Teoria do agir comunicativo, vale darmos um passo anterior na história e revisitarmos a própria filosofia clássica, com o método socrático e platônico de construção do conhecimento. Ursula Wolf, em sua obra La filosofía y la cuestión de la vida buena, retoma Platão e o modelo socrático de constituição da subjetividade, trazendo ao centro de tal constituição o sentido de elencos. A observação que se põe indica para uma diferença entre o método da téchne e o método do elencos: "não apenas evidencia a insuficiência do método da téchne para a ética [...], mas estabelece, ao mesmo tempo, um novo método, o qual tem seu modelo nos diálogos com os quais Sócrates põe à prova o saber de seus companheiros. Esse modo de proceder é o do elencos"7. Em primeiro lugar deve-se destacar a consciência da tensão dialética que se estabelece no momento em que ocupo meu espaço de sujeito portador de voz e com papel efetivo no elenco de atores. No momento que ocorre esse jogo entre atores, no sentido de elenco, se efetiva o real sentido de diálogo, enquanto meio de constituição da subjetividade, enquanto meio dialógico que constituo e me constitui.

Este é o locus próprio e ideal para que ocorra a resistência apontada por Adorno, no momento em que me é permitida a elevação do nível de consciência mediante a experiência comunicativa com outros atores. Continuando com Wolf, isso ocorre pelo fato de o elencos permitir a complementação das opiniões individuais, evidenciando a falta de clareza conceitual e elaborando as contradições. Assim se constitui um meio próprio no qual se examinam as opiniões e se constituem referenciais interpretativos acerca do próprio contexto no qual os indivíduos estão inseridos. Embora Habermas se situe em um contexto pós-metafísico, é possível perceber uma conexão entre o sentido grego de elencos e o

6 ADORNO, T. Educação e emancipação. 3. ed. Tradução de Wolfgang Leo Maar. São Paulo: Paz e Terra, 2003. p. 64-65.

7 WOLF, Ursula. La filosofía y la cuestión de la vida buena. Traducción de Ángel Galán Buján. Madrid: Editorial Síntesis, [s.d]. p. 54. 
sentido de ação comunicativa e discurso por ele desenvolvido. Ambos apontam para ações interativas por meio da linguagem, livres de coações e visando resolver problemas comuns. O que deve ser evidenciado - mesmo que apressadamente - é que, tanto no conceito de elencos, quanto na noção de comunicação de diferenciados e na teoria do agir comunicativo, a interação entre os indivíduos se torna decisivo no ato de expressão, dependendo da qualidade de tal interação a qualidade e o rigor a partir dos quais algo é dito.

O conceito de comunicação é decisivo para a compreensão existente entre o conceito de concreto e aproximação, o que se desenvolverá nos dois itens que seguem.

\section{A vinculação entre experiência e racionalidade estética}

Com a Teoria estética, Adorno põe em questão a dinâmica da subjetividade que se constitui mediante relação do sujeito com o mundo e sua consequente objetivação, enquanto expressão dessa riqueza subjetiva ou seu conteúdo de consciência. Antes da própria arte, o contexto concreto no qual o indivíduo está inserido - as experiências que determinam nosso modo de compreender a realidade - tem o poder de "pôr em movimento processos de pensamento". Essa expressão, utilizada na Teoria estética, ao comentar as obras de Brecht, deve ser considerada de modo mais amplo, direcionada ao próprio meio concreto no qual o indivíduo está inserido, o qual significa, para Adorno, impulso ao pensar.

Vicente Gómez, ao situar o sentido que a estética tem em Adorno, afirma que essa "não significa simplesmente teoria da arte, mas "é referir-se à posição que o pensamento ocupa diante da objetividade'". Essa posição do pensamento é a única, para Adorno, "capaz de realizar o verdadeiro conhecimento, e não a mera tautologia ou reduplicação do

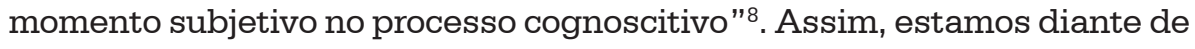
um problema filosófico: o que é a objetividade, o que é o concreto, e como é possível a compreensão não tautológica deste por parte do ser humano.

O motivo para isso está no fato de o próprio conceito de concreto ser considerado por Adorno de modo negativo: "Aquilo que ainda não era é o concreto", sendo que o maior problema é "tratar a concreção como dado, como indubitavelmente 'existente'"9. No real, no concreto, está a possibilidade de gerar processos de pensamento pelo fato de que

8 GÓMEZ, V. El pensamiento estético de Theodor W. Adorno. Madrid: Ediciones Cátedra, 1998. p. 49.

9 ADORNO, T. Teoria estética. Tradução de Artur Morão. Lisboa: Edições 70, 1993. (Arte e Comunicação: 14). p. 156. 
"aquilo que é, é mais do que ele é. Esse mais não lhe é anexado de fora, mas permanece imante a ele" ${ }^{10}$, constituindo-se em radical desafio ao pensamento, no momento em que nos deparamos com os limites de apreender somente o disponível pela experiência imediata. É diante dessa compreensão de concreto que deve ser situada não somente a expressão artística, a obra de arte, mas toda objetividade que se põe como desafio ao pensamento. Enquanto concretude que se converte em algo que está para além do seu simples existente, sendo mais do que aquilo apreendido imediatamente pelos sentidos, todas as experiências, enquanto experiências formativas, devem desencadear processos de pensamento.

Deve-se destacar a centralidade que esse conceito - concreto adquire em Adorno. Se, na filosofia clássica, a admiração, o espanto é o que origina o pensamento, a filosofia, em Adorno esta função é assumida pelo concreto. A Dialética negativa aponta isso, quando lemos que "não se deve filosofar sobre o concreto, e sim muito mais a partir dele"11. Porém, é possível salvar a admiração enquanto olhar que não se acomoda diante do evidente e imediato, mas encontra seu incitamento no descortinar desta novidade que surge: há algo ainda a compreender, conteúdo ainda a ser transmitido e apreendido, o mundo ainda não está resolvido sob a luz do sentido já manifestado. A partir de então já se evidencia a relação entre comunicação/linguagem e concreto.

Esta característica da arte, a qual deve ser ampliada para além do domínio artístico, pois tudo é mais do que aquilo que se apresenta, permite pontuar o significado da negatividade. No momento em que o entendimento não consegue perceber nada além daquilo que imediatamente aparece diante de mim, quando desfaço a possibilidade do concreto, substituindo-o pela clareza absoluta de sentido, aniquilo a possibilidade da compreensão deixando espaço para o reducionismo ou pobreza de sentido. Uma obra literária chamada $A$ condição humana ${ }^{12}$, nos evidencia a ausência de clareza diante do concreto. Nessa obra, André Malraux apresenta, já nas primeiras páginas, a relação do assassino com a vítima. Faltando ao olhar do algoz o contemplar do corpo daquele que seria morto, a ação não apresentava nenhum problema. Porém, no momento em que o olhar assassino entra na luminosidade provinda do corpo do outro, é que seu braço freia e inicia um processo de reflexão e,

10 ADORNO, T. Dialética negativa. Tradução de Marco A. Casanova. Rio de Janeiro: Jorge Zahar Ed., 2009. p. 140.

11 ADORNO, T. Dialética negativa. Tradução de Marco A. Casanova. Rio de Janeiro: Jorge Zahar Ed., 2009. p. 36.

12 Ver a tradução para o português feita por Ivo Barroso, pela editora Record, em 2008. 
então, Malraux põe o leitor diante daquilo por ele denominado mundo dos homens - o mundo onde a vida palpita.

É isso que o sentido de concreto permite, a colocação do é para além daquilo que aí está. Desse modo, o negativo, o concreto, se transforma em fundamento epistemológico, lançando-nos para a reflexão. Esse problema nos põe diante da crítica ao simples existente empírico, ocorrendo, assim, o questionamento daquilo que nos é familiar, pondo no centro das discussões aquilo que é estranho, o para além daquilo que é e que constitui o outro do meu entendimento, a alteridade. Aqui está a decisiva atualidade do estético, a novidade no modo de compreender esse termo. Para Nadja Hermann,

Desde o século 20 são conhecidas as profundas transformações ocorridas no pensamento, que [...] denunciam o caráter excludente do conceito, que não reconhece o outro e não acolhe aquilo que escapa as suas determinações e apontam para a atualidade do estético, para além da teoria do belo e da arte, transposto agora para vida cotidiana. Esse conjunto de mudanças produz efeitos sobre nossas interpretações de mundo e no modo de pensar ${ }^{13}$ (grifo nosso).

Continuando com o argumento anterior, tem-se, então, a inserção do outro e do estranho em contraposição ao idêntico e com o simplesmente familiar. Isso se deve à experiência estética, na qual, devido ao elemento do concreto e de não evidência, se "enfatiza uma multiplicidade de dimensões do estranho, que nos retira da conformidade com o familiar" ${ }^{14}$.

É o que se pode observar, por exemplo, em obras como Guernica, de Pablo Picasso. Nessa obra, percebe-se que se demarca o âmbito do concreto e de ausência de evidência, convertendo aquilo que aparece em algo que vai além de sua manifestação imediata. Essa é a particularidade da obra de arte, pela sua linguagem expressa um conteúdo que, ao mesmo tempo em que aparece, revela um ser-a-mais, ou seja, o concreto, na consideração para além do evidente. Mas esse além não é algo anexado de fora, mas conteúdo intrínseco que precisa ser disponibilizado à consciência.

Se comunicar pressupõe linguagem, é possível dizer que nesta está a formalização do conteúdo espiritual. Um pensamento expressado é um conteúdo que se torna linguagem e, desse modo, assume uma forma. A obra de arte é forma, expressão de um conteúdo. A resposta

13 HERMANN, N. Autocriação e horizonte comum - ensaios sobre educação ético-estética. Ijuí: Ed. Unijuí, 2010. (Coleção Fronteiras da educação). p. 123-124.

14 HERMANN, N. Autocriação e horizonte comum - ensaios sobre educação ético-estética. Ijuí: Ed. Unijuí, 2010. (Coleção Fronteiras da educação). p. 124. 
à questão sobre qual é o elemento decisivo - a forma ou o conteúdo -, nos remete à impossibilidade de um existir sem o outro. Conteúdo não formalizado, não tornado linguagem, é mudo e sem consequências; forma, linguagem, vazia de conteúdo, é ideológica e nociva ao desenvolvimento da consciência. Partindo desses dados, na obra de arte deve haver o equilíbrio entre o conteúdo e a forma, no sentido de aquilo expresso como conteúdo ser indício do concreto e, do mesmo modo, a forma deve permitir o surgimento deste conteúdo concreto.

Utilizando as palavras de Adorno, temos: "A forma estética é a organização objetiva de tudo o que, no interior de uma obra de arte, aparece como linguagem coerente. É a síntese não violenta do disperso"15. O elemento de não violência poderia fazer supor a primazia do conteúdo sobre a forma, pois esta pode ter a pretensão de reter aquilo que é diferente em uma imposição de sentido. Salvo esta consideração, a forma é salva pelo fato de ser indispensável na organização, na coerência da própria obra mesma. Pela forma deve haver a manifestação do conteúdo, aquela é a condição para este: "O êxito estético depende essencialmente de se o formado é capaz de despertar o conteúdo depositado na forma"16.

O conteúdo da obra de arte assume, por sua relação com o concreto, a dimensão de crítica. Deve fazer surgir o mais naquilo que está dado, esse elemento de para além do imediato, do evidente, do óbvio. Ao permitir a manifestação da novidade, ao fazer aparecer o novo, o concreto no para além do que aparece, a forma deve expressar esse conteúdo e, em uma tensão dialética, o conteúdo assumir uma forma. Vislumbra-se a convergência entre forma e crítica, pois nas "obras de arte, a forma é aquilo mediante o qual elas se revelam críticas em si mesmas [...]. Pela sua implicação crítica, a forma aniquila as práticas e as obras do passado. A forma contradiz a concepção da obra como algo de imediato" ${ }^{17}$. Assim, se visualiza a participação da arte no processo de esclarecimento, neste desenvolvimento da consciência diante daquilo que é e pelo questionamento do sentido atribuído a esse é.

Essa tensão também demarca o âmbito do que é arte, quando as obras fazem surgir o concreto ao negarem aquilo que se quer como o concreto. É diante desses elementos que se pode inserir o sentido de sujeito em relação à obra de arte. Ao pensar sobre o que é o sujeito, precisamos

15 ADORNO, T. Teoria estética. Tradução de Artur Morão. Lisboa: Edições 70, 1993. (Arte e Comunicação: 14). p. 165.

${ }^{16}$ ADORNO, T. Teoria estética. Tradução de Artur Morão. Lisboa: Edições 70, 1993. (Arte e Comunicação: 14). p. 161.

17 ADORNO, T. Teoria estética. Tradução de Artur Morão. Lisboa: Edições 70, 1993. (Arte e Comunicação: 14). p. 165. 
refletir "sobre o que na arte fala; eis o seu verdadeiro sujeito, e não o que a produz ou a recebe" ${ }^{18}$. Continuando com a argumentação, Adorno propõe:

Verdadeira é a arte, tanto mais que o que nela fala e ela própria estão cindidos, não reconciliados, mas esta verdade cabe-lhe em sorte quando ela sintetiza o dividido e assim o determina apenas no seu caráter irreconciliável. Paradoxalmente, a arte tem de testemunhar o irreconciliável e tender, no entanto, para a reconciliação; isso só é possível a partir da sua linguagem não-discursiva. Só neste processo se concretiza o nós. Mas o que fala na arte é verdadeiramente o seu sujeito, na medida em que nela fala e por ela não é representado ${ }^{19}$.

Por ser portadora de linguagem e portadora de conteúdo, a obra de arte assume a função de sujeito, ela fala, propõe questão, converte-se em desafio ao outro sujeito, agora o humano, exigindo deste o rigor cognitivo, porém, em uma posição de não domínio frente à obra. Compreende-se, então, desse modo, que a tensão entre a obra de arte e o ser humano é uma tensão entre sujeitos, não mais de sujeito e objeto, propondo algumas características especiais.

A noção de sujeito é condição para a obra de arte e esta relação entre sujeitos demarca a constituição da obra artística: um deve remeter ao outro, a arte deve remeter à razão; o ser humano com sua racionalidade deve remeter-se à arte em sua linguagem enquanto testemunha do concreto. Assim, constitui-se a racionalidade estética, nessa tensão que pode ser entendida como relação entre sujeitos, pois ambos são portadores de sentido em manifestação e propõe sentido. Ambos os sujeitos em sentido concreto. O desafio ao sujeito humano está na capacidade de perceber este sentido manifesto por este seu outro.

Estamos diante do mais rico sentido de dialética, em Adorno, o qual se converte em imperativo para o pensamento: "pensar de tal modo que a forma do pensamento não mais torne seus objetos coisas inalteráveis que permanecem iguais a si mesmas; a experiência desmente que eles o sejam"20. No núcleo do pensamento dialético está a primazia da experiência de sujeitos que não permanecem iguais no decorrer da história, rompendo com o ideal de identidade a partir do conceito. Ao mesmo tempo em que o singular não coincide com o conceito, afirmando sua dignidade de diferenciado, ele é passível de interpretação e se

18 ADORNO, T. Teoria estética. Tradução de Artur Morão. Lisboa: Edições 70, 1993. (Arte e Comunicação: 14). p. 190.

19 ADORNO, T. Teoria estética. Tradução de Artur Morão. Lisboa: Edições 70, 1993. (Arte e Comunicação: 14). p. 191-192.

20 ADORNO, T. Dialética negativa. Tradução de Marco A. Casanova. Rio de Janeiro: Jorge Zahar Ed., 2009. p. 134. 
constitui em reserva de sentido. Daí a ênfase de Adorno, na Teoria estética, em definir o momento da razão interpretativa diante do outro.

A afirmação acima, de que a relação entre sujeitos é marca da racionalidade estética, pelo fato de a própria arte se constituir em sujeito, exige um complemento. O que diferencia o sujeito humano? Em uma palavra: a consciência, e a capacidade de síntese operada pelo pensamento humano. Porém, síntese não absoluta, mas aberta à ampliação de sentido - síntese não final, mas dinâmica. Na Dialética negativa visualiza-se essa especificidade do sujeito humano, pondo como primeiro a noção de empiria, para, somente após, ser possível falar em transcendental, espiritual. A consciência é, em primeiro lugar, empírica, "função do sujeito vivo" e, portanto, histórica. Não havendo "qualquer relação com uma consciência empírica, com a consciência do eu vivo, não haveria nenhuma consciência transcendental, puramente espiritual" 21 (grifo nosso). A expressão consciência do eu vivo situa-se em um contraponto ao eu penso cartesiano. Eu penso, logo existo, como quis Descartes, é contraposto pelo imperativo dialético do pensamento: eu vivo, logo posso pensar.

A mímesis, enquanto ato de assimilar e compreender o qualitativo do outro, marca a postura essencialmente humana em relação ao mundo objetivo e encontra seu fundamento na estética. A mímesis é humana por envolver essa relação objetiva e, ao mesmo tempo, constituir consciência, subjetividade. A partir dessa constituição é que toda relação pode ser estabelecida, conectando a experiência moral e cognitiva com esta capacidade de perceber o mundo. Para Douglas Garcia Alves Júnior, esse caráter mimético nos diferencia do animal irracional, pois a assimilação animal

não é mímesis porque não configura nenhum âmbito subjetivo. Isso equivale a dizer que a mímesis é a relação primária do humano com o mundo, de sujeito e objeto. Antes de ser cognitiva ou moral, essa relação é estética. Ou melhor, ela só poderá ser cognitiva e moral sendo estética ${ }^{22}$.

Isso nos permite situarmos a estética como fundamento do humano, a partir do qual serão estabelecidos os posicionamentos diante da realidade, sejam em termos de ideias - portanto, em nível teórico -, quanto em atitudes práticas. Pôr a estética como base que nos constitui equivale nos questionarmos como percebemos o outro, como percebemos

${ }^{21}$ ADORNO, T. Dialética negativa. Tradução de Marco A. Casanova. Rio de Janeiro: Jorge Zahar Ed., 2009. p. 159.

22 ALVES JÚNIOR, D. Dialética da vertigem: Adorno e a filosofia moral. São Paulo: Escuta; Belo Horizonte: Fumec/FCH: 2005. p. 277. 
a nós mesmos, a partir dos quais iremos atribuir valor. O grande problema ético e intelectual está em substituirmos a realidade por pré-conceitos, pré-julgamentos, interpretação sem a devida formação de referenciais baseados na percepção própria, portanto, via experiência estética com o mundo.

Apesar de a vida ser o elemento originário, o ser humano se posiciona diante dela a partir da razão interpretativa, e esta é pensamento e constitui pensamento - esse é o vínculo entre experiência estética e racionalidade. A obra de arte "não dispensa objetivamente a interpretação, como se nada houvesse para interpretar [...]. A obra de arte, que crê possuir o conteúdo a partir de si, encalha num racionalismo ingênuo"23. Dessa maneira, percebe-se a relação não somente da arte com a sociedade, com o concreto, mas da arte com a razão interpretativa. Porém, a interpretação não significa clareza total de sentido, pois isso eliminaria a noção adorniana de concreto e o momento que a Filosofia ocupa diante da concretude e a própria concepção de estética como fundamento. Ou seja:

se a verdade que as obras de arte contêm ficar encerrada no momento da experiência estética, ela se perderia e esta não seria nada. Disto vem que as obras de arte, por causa daquilo que nelas aponta para além do momento fugaz da experiência estética, são remetidas à razão interpretativa, para que a interpretação exponha a verdade: para Adorno, interpretação significa interpretação filosófica; a 'necessidade de interpretação' que as obras de arte possuem é a necessidade que a experiência estética possui da demonstração filosófica ${ }^{24}$.

Isso faz retomar o sentido clássico de thaumazein, esta admiração que permitia ao ser humano pensar, filosofar, e que a própria filosofia eliminou no momento em que se viu na posição de poder apreender o fato, e fenômeno, o empírico, em uma cápsula conceitual, encerrando a própria verdade nessa cápsula. Esta permanência da thaumazein, a qual se origina no momento em que permito o novo (para a consciência à qual nada há de novo, não é possível a admiração), equivale, para usar uma expressão de Hermann, à promessa de vida. A obra de arte encontra aqui seu local privilegiado: "a arte nos indica que o mundo não é plenamente compreendido no âmbito conceitual e que pode deixar um espaço para uma promessa de vida"25. Nada há para se admirar no

${ }^{23}$ ADORNO, T. Teoria estética. Tradução de Artur Morão. Lisboa: Edições 70, 1993. (Arte e Comunicação: 14). p. 40.

24 WELLMER, A. Sobre la dialéctica de modernidad y postmodernidad: la crítica de la razón después de Adorno. Traducción de José Luis Arántegui. Madrid: Visor, 1993. (Colección La Balsa de la Medusa, 59). p. 19.

25 HERMANN, N. Autocriação e horizonte comum - ensaios sobre educação ético-estética. Ijuí: Ed. Unijuí, 2010. (Coleção Fronteiras da educação). p. 45. 
conceito; esse, em linguagem adorniana, é frio e sem consequência. A riqueza de mundo só é possível por uma via: fazendo o movimento ao encontro do mundo, ao encontro do outro - esse encontro, quando aberto à sua novidade, aprofunda o mundo. Nos deparamos, então, com o conceito de aproximação.

\section{A dinâmica entre aproximação do outro e construção de si}

A Teoria estética lança uma compreensão de obra de arte enquanto identidade consigo mesma. Nesse sentido, a arte não pretende ser idêntica ao seu exterior, mas quer ser apenas ela mesma e não representação fidedigna. Na construção do sujeito estético o primado está em ser para si, em um impulso de construção de si. Essa construção não significa desarmonia em relação ao todo, sobreposição de si mesmo, mas, sim, o fortalecimento subjetivo em sua identidade consigo mesmo, como condição para pensar uma possível identidade não opressora. Hermann destaca isso de modo incisivo, ao afirmar que a devida atenção àquilo que é particular, em sua contingência, pode

esclarecer a relação recíproca entre o universal e o particular [e] evita uma orientação puramente abstrata, sem abandonar princípios universais, pois a educação pressupõe um processo de inserção num mundo compartilhado de valores e crenças, sem o qual qualquer dialética entre individualização e socialização estaria condenada ao fracasso ${ }^{26}$.

Continuando o pensamento, para a autora, há "um mínimo de normas morais, validadas intersubjetivamente, que constituem nosso ethos e, sem as quais, se torna muito difícil edificar a formação humana. $O$ compartilhamento de valores e regras comuns permite projetar um mundo sob o qual se dá a base de nossas conversações" ${ }^{27}$. Dessa forma, percebe-se a dinâmica que ocorre entre a aproximação do/com o outro e a construção de si, indicando o real sentido de pensar a relação segundo o modelo do elencos, a dinâmica que põe os diversos atores como responsáveis pela autoconstrução e pela coesão do todo. Somente quando a proximidade permite a própria identidade é que se torna possível projetar uma situação em que a diferença é motivo de coesão, não de rupturas. O contrário, quando a aproximação impede o si mesmo, a individualidade, o "compartilhamento de valores e regras comuns" é

${ }^{26}$ HERMANN, N. Autocriação e horizonte comum - ensaios sobre educação ético-estética. Ijuí: Ed. Unijuí, 2010. (Coleção Fronteiras da educação). p. 104.

27 HERMANN, N. Autocriação e horizonte comum - ensaios sobre educação ético-estética. Ijuí: Ed. Unijuí, 2010. (Coleção Fronteiras da educação). p. 105. 
impossibilitado, ou ocorre somente de modo aparente. E isso devido ao fato de a coerção gerar coesão somente aparente.

Sob esta ótica, o pensamento pode significar um modo de aproximarse do outro, cuja dinâmica é o desencadear compreensivo gerado pela aproximação real, efetiva, que nos põe face-a-face. Com a aproximação, se estabelece a relação oposta à dominação gerada pela capacidade de distanciamento, a qual pressupõe indiferenciação - a dominação é possível somente para quem é indiferente, e para ser indiferente não pode ocorrer a aproximação efetiva. A racionalidade da aproximação não compactua com a tendência ao equivalente, que marca a forma de relação sob a ótica da instrumentalidade e do princípio da disponibilidade. É exatamente pelo fato de o outro não estar simplesmente disponível a mim e ao meu intelecto que me obriga a não tratá-lo como simples objeto do meu querer (instrumentalização). Nessa dinâmica é que deve ser pensada a tensão entre aproximação e diferenciação, aproximação e construção. A aproximação que gera diferenciação permite a construção, tanto do si quanto do outro e, até mesmo, construção do todo.

O termo fragmentos de alteridade, utilizado por Adorno na Teoria estética, indica esta racionalidade orientada por uma síntese que não desfaz a alteridade. A própria possibilidade de aproximação envolve a possibilidade de haver um inteiramente outro, como um fragmento de alteridade que faz, também, parte da própria possibilidade de aproximação, enquanto comunicação de diferenciados. Na relação com meu diferente, na diferença específica entre nós, estou em relação com o que eu não sou, mas que, ao mesmo tempo, permite fazer de mim uma singularidade. Se houver alguma síntese - no sentido de conhecimento -, contudo ela não extingue tais fragmentos, os quais permanecem no diferenciado.

Os fragmentos de alteridade interferem no processo de síntese operada pelo entendimento. No momento em que consigo referir todas as representações a mim, enquanto ser de experiência, esta síntese não é uma simples imposição ao real, pois para além de toda compreensão reside a possibilidade da novidade, do renovar da experiência diante de algo que é sempre inteiramente outro. Assim, com o termo dialética negativa, ocorre o esforço por "colocar no lugar do princípio de unidade e do domínio totalitário do conceito supraordenado a ideia daquilo que estaria fora do encanto de tal unidade"28. É ilusão a crença de que, pela tentativa de unidade, nada reste do outro. A filosofia pode se orientar pela tendência do uno, mas não pode negar a fraqueza do conceito

${ }_{28}$ ADORNO, T. Dialética negativa. Tradução de Marco A. Casanova. Rio de Janeiro: Jorge Zahar Ed., 2009. p. 08. 
ao estabelecer o uno, como que havendo um envolvimento total das particularidades nessa totalidade.

Em sentido contrário, a dialética negativa substitui esse feitiço por aquilo que existe fora dele. Um segundo giro copernicano colocaria no centro do debate filosófico os fragmentos de alteridade, aquilo que resta depois de satisfeita a sanha de tudo abocanhar. Nisso está o sentido de dialética, já que "seu nome, não diz inicialmente senão que os objetos não se dissolvem em seus conceitos, que esses conceitos entram por fim em contradição com a norma tradicional da adaequatio" ${ }^{29}$. Não ocorrendo total adequação entre conceito e objeto, acaba por não ocorrer a adequação total entre consciência e mundo real, o que viria a salvar a concretude e, exatamente por não serem objetos completamente apreensíveis, é que têm a capacidade de pôr em movimento processos de pensamento, processos de compreensão que se efetivam pela aproximação.

Considerando a estética enquanto relação entre diferenciados sem a ânsia de posse, como alteridades permanentes, o caráter de aproximação assume efeito decisivo de aparição. Não somente eu percebo o outro, ou seja, não é unicamente ato de minha consciência, mas também é o outro que aparece, que se lança ao meu olhar, se deixa apreender. A atitude estética é a secularização do ato religioso da revelação: duas presenças que se põem em direção uma à outra, para um encontro que resulta no ápice da experiência e permita a construção de sentido tão somente a partir disso.

Chegamos, então, ao conceito de construção, no qual não ocorre a prioridade dos processos subjetivos. É possível afirmar a concordância de Adorno com o ideal de construção grego clássico:

o bloco de mármore e as teclas de um piano nas quais respectivamente uma escultura e uma composição esperam ser libertadas são, para tal tarefa, provavelmente mais do que metáforas. As tarefas trazem em si a sua solução objetiva, pelo menos no interior de uma certa margem de variação, embora não possuam a univocidade de equações. A ação do artista é o ponto mínimo entre o problema a mediatizar, perante o qual ele se vê e que já está de antemão traçado, e a solução que igualmente se encontra de modo potencial no material. Se ao utensílio se chamou um braço prolongado, poder-se-ia chamar ao artista um utensílio prolongado, utensílio da passagem da potencialidade à atualidade ${ }^{30}$.

29 ADORNO, T. Dialética negativa. Tradução de Marco A. Casanova. Rio de Janeiro: Jorge Zahar Ed., 2009. p. 12.

30 ADORNO, T. Teoria estética. Tradução de Artur Morão. Lisboa: Edições 70, 1993. (Arte e Comunicação: 14). p. 190. 
Na Teoria estética ocorre a suspeita diante da posição de um sujeito que constrói, em uma adequação do material a uma forma existente na mente de tal sujeito. A tendência de Adorno está mais em conceber a capacidade de mediação para as possibilidades já existentes no material: "tudo ainda lá está. No teclado de qualquer piano está contida a Appassionata, só que o compositor deve extraí-la e, para isso, naturalmente, é preciso ser Beethoven" ${ }^{31}$. E nesse ato, não há a posse plena de tais momentos pelo sujeito, pois

implica sempre o primado dos procedimentos construtivos em relação à imaginação subjetiva. A construção impõe soluções que o ouvido ou o olho que as representam não têm imediatamente presentes em toda a claridade. O imprevisto não só é efeito, mas possui igualmente um lado objetivo. Isso se encontra modificado numa nova qualidade ${ }^{32}$.

No conceito de construção e imprevisto evidencia-se a relação não de um sujeito sobre um objeto passivo, mas uma dinâmica construtiva na qual os dois polos, tanto o artista quanto material, são atuantes no ato produtivo. O que não significa espontaneísmo, como que em um agir do indivíduo desprovido de critérios racionais, de procedimentos técnicos especializados, mas indica tão somente, usando o exemplo da composição ao piano, a necessidade de extrair aquilo que já está posto no instrumento. Não imponho um som, apenas permito a manifestação das possibilidades já existentes no instrumento.

Nessa dinâmica de construção e possibilidade do imprevisto, na qual se insere a surpresa ou a novidade vinda da própria obra, Adorno insere a categoria do novo. Com isso, de imediato, é possível indicar a contraposição de obras padronizadas ao gosto do cliente, na mercantilização das produções cujo critério é o modismo, e na possibilidade de o cliente projetar suas emoções, o que é, em grossas palavras, o produto da indústria cultural. A contraposição ao novo, sugerida aqui, autoriza-se pela característica imediatamente oposta, a do sempre-semelhante.

A produção em série - seja da arte ou dos bens de consumo, e nesse caso a própria arte seria um bem de consumo - acompanha o padrão do sempre-semelhante e, visualizando a educação, visualizando o próprio humano, impede a manifestação da riqueza constitutiva interna, a possibilidade de ser não-idêntico, o não-semelhante, a própria

31 ADORNO, T. Experiência e criação artística - paralipômenos à "Teoria Estética". Tradução de Artur Morão. Lisboa: Edições 70, 2003 (Arte e Comunicação: 81). p. 24.

32 ADORNO, T. Teoria estética. Tradução de Artur Morão. Lisboa: Edições 70, 1993. (Arte e Comunicação: 14). p. 36. 
manifestação do novo que é cada ser humano. Visualiza-se, aqui, um extraordinário sentido para o ato educativo, o qual deve permitir a manifestação qualificada da riqueza constitutiva do indivíduo, enquanto algo novo e, nessa autoconstrução de si, gerar a identidade de si, a construção do próprio sujeito.

Porém, esse novo, conforme já destacado, não é algo imposto de fora, mas é a manifestação de algo já existente, porém não evidenciado. Enfaticamente, o novo é somente aquilo que permite romper com o sempre-semelhante, conduzindo a conceitos como outro e alteridade. "A relação ao Novo tem o seu modelo na criança que busca no piano um acorde jamais ouvido, ainda virgem. No entanto, o acorde existia já desde sempre. As possibilidades de combinação são limitadas; na verdade, tudo já se encontra no teclado" 33 . O desafio está em fazer com que o outro perceba esse novo em si mesmo e, não menos importante, conseguir perceber isso no outro. No novo está, então, a expressão do concreto, a manifestação para além daquilo que está evidente, reafirmando o sentido de dialética: "A dialética é a consciência consequente da nãoidentidade" 34 . Em primeiro lugar cabe destacar que, partindo dessa ideia, a dialética não é um método, mas um modo de consciência. Consciência esta adquirida após romper com a ideológica concepção de pensamento com função exclusivamente identificadora. Assim, temos a impossibilidade de haver identidade e, ao mesmo tempo, existir a dialética - a dialética se opõe ao pensamento identificador: pensar na identidade é pensar não dialeticamente, pois anula sua condição primeira, o divergente, dissonante, negativo, diferenciado.

Conforme a Dialética negativa ${ }^{35}$, a consequência primeira gerada pela anulação da dialética promovida pelo pensamento identificador, é o empobrecimento da experiência. A aproximação não ocorre mais com o critério de permitir o novo e o diferenciado, mas enclausurando o individual dentro de padrões de validade universal. Toda a diversidade da experiência é sacrificada juntamente com a diversidade do outro, em nome de uma adequação e uniformidade abstrata:

Entre as condições sociais da educação, que encurtam, talham sob medida e estropiam multiplamente as forças produtivas espirituais, que com a indigência reinante no domínio da imaginação e nos processos patogênicos da primeira infância diagnosticados pela psicanálise,

${ }^{33}$ ADORNO, T. Teoria estética. Tradução de Artur Morão. Lisboa: Edições 70, 1993. (Arte e Comunicação: 14). p. 45.

34 ADORNO, T. Dialética negativa. Tradução de Marco A. Casanova. Rio de Janeiro: Jorge Zahar Ed., 2009. p. 13.

35 Ver, principalmente, p. $13 \mathrm{~s}$. 
mas de modo algum realmente transformados por ela, todos poderiam compreender ou mesmo apenas notar tudo. Se fosse isso o que esperamos, então regularíamos o conhecimento pelos traços patológicos de uma humanidade da qual é retirada, por meio da lei da perpetuação do igual, a possibilidade de fazer experiências, se é que algum dia ela teve uma tal possibilidade ${ }^{36}$.

O imperativo dialético do pensamento, o qual conduz à possibilidade de criar experiência, aponta a necessidade de "pensar de tal modo que a forma do pensamento não mais torne seus objetos coisas inalteráveis que permanecem iguais a si mesmas; a experiência desmente que eles o sejam" ${ }^{37}$. Os objetos aqui mencionados são os objetos do pensamento, ou seja, os conceitos, criados pelo pensamento a partir da experiência. Indicase a necessidade de construção conceitual em confronto permanente com o concreto. Assim, o conceito não é uma ferramenta a partir da qual o concreto é tratado, mas esta ferramenta é o próprio ato de pensar.

$\mathrm{O}$ conceito, enquanto resultado da relação entre pensamento e concretude, permite apenas uma compreensão daquilo a que se direciona de modo bem direto e, portanto, passível de mudança, já que o concreto sofre a ação do tempo e do próprio espaço. A própria Dialética negativa ${ }^{38}$ leva ao extremo a citação anterior, compreendendo o conceito como algo não-idêntico nem sequer a si mesmo, muito menos com aquilo ao qual se refere. Ou seja, ele se determina por aquilo que lhe é exterior, de modo que não se esgota em si mesmo, sendo impossível aos objetos do pensamento - o conceito - ser inalterável e igual a si mesmo.

A dissonância, própria das cores, sons e imagens no mundo artístico, também se converte em critério de racionalidade. É o que se percebe, por exemplo, em uma obra brasileira como o Rudepoema, de Heitor Villa-Lobos, na qual o entendimento se depara com sua insuficiência na resolução do sentido, sendo a obra, ao mesmo tempo, resistência e abertura à interpretação. Por ser resistência permanece em seu para si; enquanto abertura, é direcionada à razão interpretativa. Sendo assim, toda aproximação é sinônimo de sentido revelado e reserva de sentido. Por isso que a constituição do estético em Adorno tem como objetivo principal pôr em movimento processos de pensamento, e a verdade encontra sua significação tão somente naquilo que não está em harmonia com o sentido administrado, imposto. Ou seja, o verdadeiro surge diante daquilo que permite ao ser humano ser forma de alteridade, em sua

${ }^{36}$ ADORNO, T. Dialética negativa. Tradução de Marco A. Casanova. Rio de Janeiro: Jorge Zahar Ed., 2009. p. 42-43.

37 ADORNO, T. Dialética negativa. Tradução de Marco A. Casanova. Rio de Janeiro: Jorge Zahar Ed., 2009. p. 134.

38 Cf. p. 136. 
permanente reserva de sentido. Em outras palavras, a verdade está na aproximação, e não na apropriação.

Retomamos a noção de comunicação, pois ela se encontra incorporada a esta noção de sujeito estético. Somente há comunicação, ou diálogo, quando o pressuposto relacional for pacífico e, dessa forma, não tiver a pretensão de redução epistemológica ao sentido que o sujeito apreende ou atribui. A comunicação somente se efetiva na paz do diferenciado, quando é possível ser outro sem temor:

Se fosse permitido especular sobre o estado de reconciliação não caberia imaginá-lo nem sob a forma de indiferenciada unidade de sujeito e objeto nem sob a de sua hostil antítese; antes, a comunicação do diferenciado. [...] Paz é um estado de diferenciação sem dominação, no qual o diferente é compartido ${ }^{39}$.

A marca da comunicabilidade está na interioridade que realiza a abertura e o fechamento. A primeira, por não existir plena identidade no princípio de realidade, sendo a tensão dialética natural e pressuposto para o encontro e para a própria concepção de verdade em Adorno. A segunda, por evitar que o próprio ser humano se perca em meio ao jogo de diferenciados. Ou seja, é preciso que ocorra a identidade do sujeito consigo mesmo, o reconhecimento de sua própria subjetividade enquanto núcleo de força. Abertura e fechamento, identidade e não identidade, são condições para um sujeito provido de subjetividade - significa condição e capacidade de pensamento, bem como constituição da própria condição humana no interior do mundo.

A ênfase dada à comunicação remete ao sujeito que se constitui enquanto ser histórico, ou seja, enquanto ser-aí, enquanto presença posta e mediada pelo elemento comunicativo. É o singular caracterizado como ser-aí; não o em-si kantiano, inapreensível pelo entendimento humano, mas aquilo que está dado e, nessa presença, impossível de ser ignorado. "A comunicação com o outro cristaliza-se no singular que é mediado por ela em seu ser-aí" 40 . É fundamental destacar que a comunicação entre diferenciados é mediada pelo próprio ato de comunicação, e não nas estruturas a priori do sujeito. Nesse sentido é que se compreende a primazia da relação, cuja mediação é o ato comunicativo mesmo. A individuação é dada pela comunicação, pelo enfrentamento que busca o comum (universal) e o diferente (alteridade).

39 ADORNO, T. "Sobre sujeito e objeto". In: Palavras e sinais: modelos críticos 2. Tradução de Maria Helena Ruschel. Petrópolis: Vozes, 1995. p. 184.

40 ADORNO, T. Dialética negativa. Tradução de Marco A. Casanova. Rio de Janeiro: Jorge Zahar Ed., 2009. p. 140. 
Esta tensão entre universal e particular, a qual se mantém enquanto houver comunicação, não se caracteriza por uma relação comparativa entre individualidades. Se comunicação fosse isso, então tudo se resolveria no ato dedutivo a partir do pensamento. Por exemplo, munido dos referenciais sobre o que caracteriza um ser humano, poderíamos falar e atribuir valor sobre qualquer indivíduo, mesmo sem relação efetiva. Esse modo de proceder não pode ser denominado comunicação, pois faz-se ausente o singular que, em seu ser-aí, permite a comunicação.

O centro dessa discussão está no fato de que não é possível progredir do particular ao universal somente pela força do pensamento: "não se progride a partir de conceitos e por etapas até o conceito superior mais universal, mas esses conceitos entram em uma constelação. Essa constelação ilumina o que há de específico no objeto e que é indiferente ou um peso para o procedimento classificatório" ${ }^{41}$. Através do conceito de constelação, Adorno propõe uma congregação de momentos e sentidos que se comunicam e, sem subsumir nenhum deles, compõem a riqueza de sentido. Cabe destacar que nenhum dos momentos se eleva em potência essencial, mas todos pontuam um momento permanente (que não é negado na figura do outro momento) na constituição do sentido, de modo que não é o primado da razão doadora de sentido, mas o sentido que se forma na ligação dos momentos históricos. Constelação não é representação, mas apresentação daquilo que não pode ser compreendido isoladamente. É história que engloba o indivíduo e na qual ele está inserido. Perceber a constelação é nada mais que perceber e interpretar aquilo que é condicionado historicamente - conhecer é pensar em constelação:

Essa história está nele e fora dele, ela é algo que o engloba e em que ele tem seu lugar. Perceber a constelação na qual a coisa se encontra significa o mesmo que decifrar aquilo que ele porta em si enquanto algo que veio a ser. [...] Somente um saber que tem presente o valor histórico conjuntural do objeto em sua relação com os outros objetos consegue liberar a história no objeto ${ }^{42}$.

Com a constelação que constitui sentido via comunicação, ocorre a abertura do enigma que se quer decifrar. Adorno utiliza a metáfora do cofre para expressar o sentido que a constelação assume em sua teoria: como os cadeados em um cofre-forte, a abertura não ocorre "apenas

${ }_{41}$ ADORNO, T. Dialética negativa. Tradução de Marco A. Casanova. Rio de Janeiro: Jorge Zahar Ed., 2009. p. 142.

42 ADORNO, T. Dialética negativa. Tradução de Marco A. Casanova. Rio de Janeiro: Jorge Zahar Ed., 2009. p. 141. 
por meio de uma única chave ou de um único número, mas de uma combinação numérica" 43 .

Esse modo de compreender a linguagem tem sua origem na relação com a obra de arte, com seu modo de expressão e o que lhe dá autenticidade: "o meio pelo qual as obras de arte existentes são mais do que a existência" - ou seja, pela sua existência permitem a manifestação do concreto, do mais - este meio "não é um novo ser-aí, mas a sua linguagem. As obras autênticas falam mesmo quando recusam a aparência" ${ }^{44}$. Essa recusa da aparência volta a fazer referência ao concreto, indicando que "deveria derrubar-se a doutrina da imitação; num sentido sublimado, a realidade deve imitar as obras de arte. Mas o fato de as obras de arte existirem mostra que o não-ente poderia existir. A realidade das obras de arte dá testemunho da possibilidade do possível"45 (grifo nosso). Em última instância, o que temos é a construção de sentido, via expressão, comunicação, linguagem. Para isso, faz-se necessária a dinâmica da aproximação dos diferentes como possibilidade desta construção: do sentido desse outro, do sentido de mim mesmo, da autoconsciência.

Assim sendo, na obra de arte ocorre comunicação; ela mesma comunica. Mas não é comunicação de uma mensagem que se pode simplesmente extrair e que está evidente, sendo, antes, a manifestação do concreto. Em Adorno, a obra somente é artística se permitir tal manifestação, abrindo espaço para o surgimento do algo mais, o surgimento daquilo que é, para além do que se mostra imediatamente. Mantendo, a arte, essa relação com o concreto, sendo uma abertura para a verdade, ela se converte em impulso e possibilidade de esclarecimento, em oposição radical aos produtos da indústria da cultura. Tal momento da linguagem diante do mundo objetivo assume o caráter particular de veicular a realidade à consciência. É, então, o modo pelo qual ocorre a manifestação do outro, o que nos remete, seguindo Rodrigo Duarte, para a consciência de uma linguagem radicalmente não-pragmática e não-utilitária. Tal é o sentido próprio da constelação, em Adorno, onde "os conceitos se reúnam em torno da coisa a ser conhecida, a fim de determinar o seu potencial interno"46. A comunicação via constelação está no núcleo que estrutura o

43 ADORNO, T. Dialética negativa. Tradução de Marco A. Casanova. Rio de Janeiro: Jorge Zahar Ed., 2009. p. 142.

44 ADORNO, T. Teoria estética. Tradução de Artur Morão. Lisboa: Edições 70, 1993. (Arte e Comunicação: 14). p. 124.

45 ADORNO, T. Teoria estética. Tradução de Artur Morão. Lisboa: Edições 70, 1993. (Arte e Comunicação: 14). p. 153.

46 DUARTE, Rodrigo. "Reflexões sobre dialética negativa, estética e educação". In: PUCCI, Pedro; GOERGEN, Pedro; FRANCO, Renato (Org.). Dialética Negativa, estética e educação. Campinas: Editora Alínea, 2007. - (Coleção Educação em debate). p. 25. 
concreto, enquanto aquilo que ainda não é para os nossos sentidos e para a nossa consciência. Isso se converte em um desafio para a sociedade contemporânea, na qual a rapidez nas informações, desvinculada do rigor cognitivo, comprometem a percepção dos fatos. O grande desafio e, também, a grande beleza da era da comunicação global está em incorporar o elemento da constelação na linguagem, a partir da qual ocorreria ampliação do horizonte compreensivo, ocasionando a integração dos indivíduos em um contexto global possibilitador da ampliação no senso ético da responsabilidade diante de problemas comuns e do senso ético de saber se posicionar diante do pensamento do outro com abertura ao novo que surge dele.

\section{Considerações Finais}

A proposta de relacionar os conceitos de concreto, aproximação e construção como estando na base da constituição das experiências, a partir da Teoria Crítica de Theodor Adorno, nos leva à concepção de que o ponto de partida a partir do qual devemos reconhecer o humano é pela capacidade de constituir a subjetividade a partir do modo como percebe o outro. Estamos diante da colocação da experiência estética como fundamento do humano, não em uma experiência específica com a obra de arte, mas uma experiência que define a existência sobre nossa capacidade de percepção e o modo como nosso pensamento se posiciona diante de si mesmo e da objetividade. Vinculado a este sentido de estética exposto por Adorno ainda em Kierkegaard, a Dialética negativa e na Teoria estética lhe garantirá pleno desenvolvimento.

Alguns aspectos tornam-se vitais nesse contexto. Em primeiro lugar, a experiência somente se efetiva, seguindo o filósofo em questão, quando for possível a sintonia comunicativa entre os envolvidos. Comunicar o diferenciado significa, por um lado, admitir que existe algo ainda não manifestado, ainda não apreendido, mas que é parte constituinte de quem a expressa. Por outro lado, comunicar o diferenciado nos remete aos eventos da dinâmica histórica que estão constantemente constituindo tudo o que existe. $O$ diferenciado que surge dessa dinâmica exige do pensamento uma postura de aproximação permanente, mas uma aproximação que tem a base na percepção, sendo, então, primordialmente estética.

Em segundo lugar, cabe destacar que essa comunicação, por ter o poder de revelar o diferenciado, é expressão do concreto, daquilo que ainda não é aos nossos sentidos. Estamos diante de um ponto delicado na teoria adorniana, pois isso pode comprometer sua localização como pensador pós-metafísico. Aquilo que ainda não é, mas que está posto 
no fato, no indivíduo, não equivale ao em-si kantiano, pois este, para o filósofo da Crítica da razão pura, é inatingível ao pensamento. Para o frankfurtiano, o concreto enquanto algo ainda não dado é passível de percepção, mas depende do nível de experiências que se estabelece. Por isso que ocorre aí um radical direcionamento à razão interpretativa, à qual não tem a tarefa de atribuir sentido, mas de aproximar-se para apreender o que está posto no outro. Não é, tampouco, equivalente à essência aristotélica, pois no concreto está a permanente construção histórica e, portanto, mutável e provocadora do novo que nos caracteriza. A preocupação de Adorno está, então, em como a sensibilidade e o pensamento podem se relacionar com isso que está em permanente transformação, mas passível de apreensão. A solução pode ser dada na medida em que compreendermos a experiência como o repousar sobre o outro, demorar-se nele; na medida em que fizermos a experiência do encontro sensível e da estética como fundamento das relações.

\section{Referências}

ADORNO, Theodor W. Dialética negativa. Tradução de Marco A. Casanova. Rio de Janeiro: Jorge Zahar Ed., 2009.

. Educação e emancipação. 3. ed. Tradução de Wolfgang Leo Maar. São Paulo: Paz e Terra, 2003.

. Experiência e criação artística - paralipômenos à “Teoria Estética”. Tradução de Artur Morão. Lisboa: Edições 70, 2003. (Arte e Comunicação, 81).

. Kierkegaard: construção do estético. Tradução de Alvaro L. M. Valls. São Paulo: Editora UNESP, 2010.

Observações sobre o pensamento filosófico. In: Palavras e sinais: modelos críticos 2. Tradução de Maria Helena Ruschel. Petrópolis: Vozes, 1995. p. 15-25.

. Sobre sujeito e objeto. In: . Palavras e sinais: modelos críticos 2. Tradução de Maria Helena Ruschel. Petrópolis: Vozes, 1995. p. 181-201.

Teoria estética. Tradução de Artur Morão. Lisboa: Edições 70, 1993. (Arte e Comunicação, 14).

ALVES JÚNIOR, Douglas Garcia. Dialética da vertigem: Adorno e a filosofia moral. São Paulo: Escuta; Belo Horizonte: Fumec/FCH: 2005.

DUARTE, Rodrigo. Reflexões sobre dialética negativa, estética e educação. In: PUCCI, Pedro; GOERGEN, Pedro; FRANCO, Renato (org). Dialética Negativa, estética e educação. Campinas: Editora Alínea, 2007, p. 17-30. (Coleção Educação em Debate).

GÓMEZ, Vicente. El pensamiento estético de Theodor W. Adorno. Madrid: Ediciones Cátedra, 1998.

HERMANN, Nadja. Autocriação e horizonte comum - ensaios sobre educação éticoestética. Ijuí: Ed. Unijuí, 2010. (Coleção Fronteiras da educação). 
WELLMER, Albrecht. Sobre la dialéctica de modernidad y postmodernidad: la crítica de la razón después de Adorno. Traducción de José Luis Arántegui. Madrid: Visor, 1993. (Colección La Balsa de la Medusa, 59).

WOLF, Ursula. La filosofía y la cuestión de la vida buena. Traducción de Ángel Galán Buján. Madrid: Editorial Síntesis, [s.d.].

Recebido em maio 2012.

Aceito em dezembro 2012. 